\title{
ОБЗОР ИНТЕРНЕТ-РЕСУРСОВ, ПРИМЕНЯЕМЫХ В ПРОЦЕССЕ ОБУЧЕНИЯ АНГЛИЙСКОМУ ЯЗЫКУ
}

\author{
T. А. Николаева, О. В. Заеко \\ Московский гуманитарный университет
}

\begin{abstract}
Аннотация: В статье представлен краткий обзор Интернет-ресурсов, которые могут использоваться преподавателем на занятиях по английскому языку для реализации целей и задач курса «Иностранный язык в неязыковом вузе».
\end{abstract}

Ключевые слова: Интернет; обзор; информационный ресурс; образовательный сайт; коммуникативная компетенция; английский язык

\section{A REVIEW OF INTERNET RESOURCES USED IN THE PROCESS OF TEACHING ENGLISH}

\author{
T. A. Nikolaeva, O. V. Zaeko \\ Moscow University for the Humanities
}

\begin{abstract}
The article provides a brief review of the Internet resources that can be used by English teachers to accomplish the "Foreign Language at a Nonlinguistic University" program objectives.

Keywords: Internet; review; information resource; educational website; communicative competence; English language
\end{abstract}

Обучение студентов, поступающих в вуз, связано как с реализацией задачи дальнейшего развития полученных ими в школе языковых навыков, так и приобретением основ профессиональных знаний и компетенций. Это обстоятельство обусловлено тем, что студенты в стенах вуза овладевают иностранным языком специальности, расширяют свой кругозор, учатся межкультурной коммуникации, основам будущей научной деятельности и самообразования.

Изучение иностранного языка призвано также обеспечить, по мнению С. Г. ТерМинасовой:

- повышение уровня учебной автономии, способности к самообразованию;

- развитие когнитивных и исследовательских умений;

- развитие информационной культуры;

- расширение кругозора и повышение общей культуры студентов;

- воспитание толерантности и уважения к духовным ценностям разных стран и народов (Тер-Минасова, 2009: 5).

Использование современных информационных технологий в обучении английскому языку в настоящее время имеет важное значение, т. к. позволяет реализовать личностно-ориентированный, коммуникативно-когнитивный и социокультурный деятельностный подход к обучению иностранным языкам.

Кроме того, интернет-ресурсы, наряду с другими средствами обучения, несомненно, помогают решать целый спектр дидактических задач:

- формирование у студентов определенных навыков и умений уверенного применения иностранного языка для решения коммуникативных языковых задач 
в разных ситуациях общения в профессиональной сфере;

- развитие у студентов способности реализовывать обмен деловой информацией на иностранном языке в устной и письменной формах;

- самостоятельное осуществление поиска, накопления и расширения объема профессионально значимых знаний в процессе естественного общения с носителем иностранного языка.

Используя интернет-ресурсы, преподаватель таким образом получает дополнительные средства для создания моделей настоящего общения на уроке или вне аудитории. Так, социальные сети, выполняют функцию живого среза языка. На уроке создаются условия «погружения» в язык, т. е. выполняются задания, регламентированные особенностями и возможностями той или иной социальной сети. Таким образом, с помощью информационных интернет-ресурсов создаются естественные условия для тренировки и дальнейшего развития видов речевой деятельности (говорения, чтения, письма и аудирования), для «развития коммуникативно-когнитивных умений осуществлять поиск, отбор, классификацию, анализ и обобщение информации» (Баранова, Дубинина, 2015: 2) и стимулируется умение активно использовать иностранный язык.

Пользуясь ресурсами сети Интернет, студенты могут общаться с носителями языка в чатах, на форумах, участвовать в видеоконференциях, слушать лекции на интересующие их темы, находить аутентичные тексты и работать с ними, проверять свой уровень владения языком с помощью различных тестов, выполнять разнообразные коммуникативные упражнения как под руководством преподавателя, так и самостоятельно.

Представленный ниже перечень Интернет-ресурсов, является далеко не полным в силу того, что, во-первых, охватить все ресурсы в рамках одной статьи не представляется возможным, а во-вторых, постоянно появляются новые.

1. Интернет-ресурсы, применяемые при обучении письменным видам речевой деятельности (чтение и письмо)

Чтение - важный рецептивный вид речевой деятельности, при овладении которым обучающиеся получают информацию из письменного текста. Это ценный источник получения новых знаний о людях, истории, культуре, традициях стран изучаемого языка. Овладевая навыками чтения или развивая ранее приобретенные, студенты могут использовать информацию из аутентичных текстов, представленных в различных ситуациях иноязычного общения, в том числе в сфере будущей профессиональной деятельности.

Письмо - это продуктивный вид речевой деятельности, целью которого является изложение мыслей в письменной форме. Письменная речь дополняет устную, способствует расширению возможностей человеческого общения, т. к. обеспечивает передачу информации на расстояние, делает возможным закрепление содержания устной речи во времени.

При обучении и развитии навыков письма в неязыковом вузе студенты учатся готовить сообщения на заданную тему в письменной форме, писать эссе, учатся кратко излагать содержание прочитанного текста, прослушанного аудиоматериала, просмотренного видеофрагмента, а также овладевают приемами ведения деловой переписки и составления резюме.

Интернет предоставляет огромное количество ресурсов с текстовыми, аудио- 
и видеоматериалами по разным темам. Кроме того, в социальных сетях студенты могут общаться с носителями языка, оттачивая свои умения и навыки иноязычного общения, что способствует повышению уровня их мотивации к обучению.

Ниже предложен список популярных в настоящее время интернет-ресурсов:

- сайт Британской Вещательной Медиакорпорации www.bbc.co.uk/learningenglish предлагает разнообразные образовательные ресурсы для разных возрастных групп по уровням владения языком. Доступ к этому сайту возможен посредством социальных сетей, таких как Facebook (https://www.facebook.com/ bbclearningenglish.multimedia), Twitter (https://twitter.com/bbcle), Instagram (https:// www.instagram.com/bbclearningenglish/), YouTube (https://www.youtube.com/user/ bbclearningenglish);

- официальный сайт Британского Совета https://www.britishcouncil.org/. Британский Совет предлагает бесплатные возможности для изучения английского языка: разработаны отдельные направления для обучения детей, подростков и взрослых;

- обучающий сайт Британского Совета https://learnenglish.britishcouncil. org/ предоставляет возможность совершенствования навыков письма и чтения. Страничка сайта доступна на Facebook (https://www.facebook.com/LearnEnglish. BritishCouncil), Twitter (https://twitter.com/LearnEnglish_BC), в Instagram (https:// www.instagram.com/britishcouncil/);

- ESL Writing and Reading https://learnenglishteens.britishcouncil.org/skills — ресурсы для развития навыков письма и чтения;

- Educational Technology and Mobile Learning https://www.educatorstechnology. com/ - ресурс для преподавателей, где представлены адреса 19 образовательных сайтов, которые будут полезными для развития навыков чтения и письма;

- 10 Online Resources to Improve EL Literacy http://blog.tesol.org/;

- ESL Ideas: Improving Reading Skills by Using the Internet https://www. universalclass.com/ - представлены несколько ресурсов для совершенствования навыков чтения:

- ESL reading Smart;

- NaturalReader;

- TextAloud MP3;

- Story Place;

- Self-Study quizzes for ESL Students;

- 10 News Sites to Practice Your English Reading Skills https://blog.lingoda.com/;

- Best Websites for Independent Reading https://www.commonsense.org/ — книги онлайн, а также различные упражнения, игры и песни как для младших школьников, так и для студентов и взрослых; даны упражнения на развитие навыков чтения и письма. Упражнения систематизированы по уровням владения языком;

- 8 Excellent Digital Resources for English Language Learners https://www.ef.com/ wwen/blog/teacherzone/self-study-resources-for-students/: Reading-ESL Lounge — на этом сайте можно найти 25 упражнений для развития навыков чтения (по уровням владения языком); Writing-ESL Lounge - такой же ресурс для развития навыков письма;

- Adult Education Tutor Support http://www.eastsideliteracy.org/tutorsupport/ index.htm - полезный ресурс для студентов и особенно преподавателей: есть 
ссылки на сайты, где преподаватели могут найти планы уроков на разные темы, имеется возможность бесплатно скачать и распечатать раздаточный материал:

- Web Links to ESL Lesson Plans and Printable Worksheets;

- Web Links to Online ESL Activities for Students;

- ESL Books and Periodicals with Photocopiable Activities and Lessons;

- Other Recommended ESL Books and Periodicals;

- $\quad 50$ ESL Resources for Students: ESL Writing (https://custom-writing.org/ blog/esl-resources-for-students) - здесь можно найти полезные статьи, содержащие рекомендации по написанию эссе, упражнения на развитие навыков письма и пунктуации:

- How to avoid common mistakes in essay writing;

- Ultimate Guide to Academic Writing: 100+ Useful Resources;

- Jennifer ESL - канал на YouTube с огромным количеством полезных ресурсов: разнообразные задания и уроки с практическими советами по развитию навыка письма и многое другое для изучающих английский язык;

- Using English (https://www.usingenglish.com/) - полезные для преподавателей и студентов статьи по разным аспектам языка от грамматики до правил правописания и пунктуации. Есть возможность распечатки раздаточного материала;

- $\quad$ The Punctuation Guide (https://www.thepunctuationguide.com/) — все о пунктуации в символах;

- $\quad$ Agenda Web (https://agendaweb.org/reading-exercises.html) - здесь можно найти короткие рассказы, сказки, басни и упражнения на понимание прочитанного;

- 5 Minute English (http://www.5minuteenglish.com/) — ESL Lessons HelpingYouLearn English. Оченьполезный ресурсс разнообразными тренировочными упражнениями на развитие навыков чтения, а также грамматики, аудирования, произношения и интонирования, на расширение словарного запаса. Также можно найти разъяснения по употреблению слэнга и идиоматических выражений;

Free English Language lessons and EFL exam practice - Reading (https:// www.english-online.org.uk/theread.htm) - это электронная библиотека аутентичных книг, представленных по уровням владения языком;

- ESL Fast (https://www.eslfast.com/) - ресурс, содержащий полезные рекомендации о том, как развивать умение читать, писать эссе, а также материал по страноведению США;

- The Internet TESL Journal ESL: Reading (http://iteslj.org/links/ESL/ Reading/) - полезный и интересный ресурс для преподавателей и студентов, на котором кроме упражнений на развитие навыков чтения, есть игры, кроссворды, видео, тесты и многое другое.

2. Интернет-ресурсы, применяемые при обучении устным видам речевой деятельности (говорение и аудирование), а также грамматике.

Воспроизведение иностранной речи на слух и ее понимание - аудирование один из видов речевой деятельности и, для некоторых людей самый сложный. Успешность аудирования зависит от ряда факторов: индивидуально-возрастных особенностей слушающего; условий восприятия; лингвистических трудностей смыслового восприятия; настроенности на восприятие речи. 
Навык аудирования требует постоянной практики, при этом очень важно предоставлять студентам аутентичный материал для прослушивания. Такой материал можно найти на уже упомянутых сайтах и в приложениях, а также на следующих:

- сайт Британской Вещательной Медиакорпорации;

- официальный сайт Британского Совета;

- $\quad$ обучающий сайт Британского Совета;

- $\quad$ Randall's ESL Cyber Listening Lab https://www.esl-lab.com/ - обучающий сайт, на котором представлено много полезных материалов на развитие навыков говорения и аудирования. Заслуживают упоминания странички на платформах Twitter (https://twitter.com/eslrandall/), Instagram (https://www.instagram.com/ listeninglab/), Facebook (https://www.facebook.com/esllab/) и YouTube (https://www. youtube.com/c/esllab);

- $\quad$ ESL Lounge https://www.esl-lounge.com/ - очень полезный ресурс как для студентов, так и для преподавателей. Здесь можно найти планы уроков, весьма обширный материал для дискуссий, книги, игры, викторины, тексты песен. Этот ресурс также будет очень полезен тем, кто хочет подготовиться к международным экзаменам FCE, CAE, CPE Proficiency, IELTS, TOEFL. Что касается упражнений на развитие навыков говорения, аудирования и грамматических навыков, то будет не лишним посмотреть такие разделы, как:

- $\quad$ Full Grammar Explanation;

- Authentic English Listening and Reading Materials;

- Exercises to Help with Grammar, Vocabulary, Listening, Reading and Pronunciation;

- $\quad$ IDC https://idc.edu/practice-listening-in-english-with-these-apps-andtools/ - наэтом сайтеразмещен списокмобильныхприложений, спомощью которых изучающие английский язык могут развивать навыки говорения и аудирования:

- Busuu (https://www.busuu.com/) - это обучающее приложение, которое поможет научиться говорить, слушать, правильно использовать грамматические конструкции, улучшить произношение в английском языке. Данный образовательный ресурс дает возможность слушать аудиоматериалы на разных диалектах английского языка. Кроме того, в этом приложении есть возможность ставить аудиозапись на паузу, перематывать назад или вперёд и повторно прослушивать, совершенствуя свои навыки в аудировании и произношении;

- $\quad$ Ello http://elllo.org/ - бесплатная онлайн библиотека аудио и видео клипов. Также здесь имеется раздаточный материал к урокам, который будет, несомненно, полезен преподавателю в процессе подготовки к занятию;

- $\quad$ English Listening Practice - World Talks (https://apps.apple.com/us/ app/english-listening-practice-world-talks/id527374208) - это приложение для IOS. Содержит более 1100 интервью, а также возможность прослушивать так называемые «микшерные» уроки (mixer lessons), когда, например, шесть разных людей отвечают на один и тот же вопрос, но говорят при этом на шести разных диалектах английского языка. Приложение содержит также упражнения на проверку понимания прослушанного текста;

- $\quad$ LearnEnglish Podcasts (https://learnenglish.britishcouncil.org/apps/learnenglish-podcasts) - это приложение разработано Британским Советом. Содержит интересные интервью с людьми на самые разные темы (знаменитости, еда и др.). 
20 часов подкастов можно слушать бесплатно. К каждому аудио-эпизоду есть скрипт и вопросы на проверку понимания;

- $\quad$ Listen Pal (https://apps.apple.com/app/id1057051351) - приложение мобильных телефонов, планшетов и компьютеров, работающих на платформе Apple. Содержит популярные развлекательные видео из Интернета с субтитрами. В этом приложении пользователь может смотреть и слушать видео из YouTube и его популярных каналов Mental Floss, Yoga и многое другое;

- $\quad$ Speak English Fluently http://speakenglishdaily.com/ - приложение, которое дает возможность научиться вести беседу с американским носителем языка;

Tandem (https://www.tandem.net/) - сообщество по изучению английского языка. Студентов объединяют в пару с носителем языка для практики. Способобщения обучающиеся выбирают сами, это могут быть текстовые сообщения, аудио или видео файлы;

English Listenings (https://englishlistenings.com/) - сайт, специально созданный для ESL преподавателей и студентов. Содержит более 500 аудиоэпизодов, рассчитанных на студентов с разным исходным уровнем владения языком. Нам представляется ценным тот факт, что сайт содержит опцию выбора акцента говорящего.

На наш взгляд, особого внимания заслуживают ресурсы социальной сети Instagram.

\section{Полезные ресурсы в социальной сети Instagram}

- $\quad$ skyteach_community https://www.instagram.com/skyteach_community/ образовательная страница в Instagram, которая будет полезной как для преподавателей, так и для студентов. Здесь можно найти:

- огромное количество игр и других занятий, которые помогут оживить урок, например: пост «5 игр для cool-down со взрослыми» или «5 игр для cooldown с детьми» (игры для завершения урока);

- серия публикаций по страноведению: «Что посмотреть/послушать/ почитать, чтобы узнать больше об Англии/Шотландии/Ирландии/Австралии/ США». А также публикации на тему праздников в англоязычных странах, например: «День Благодарения» или «День Друзей в США»;

- множество публикаций для повышения уровня квалификации преподавателей, например: «Ресурсы для повышения квалификации преподавателя», «Какие приложения будут полезны учителю английского», вебинары «Как обучать поколение Z, используя их любовь к гаджетам» или «Digital Tools for Creativity in the Classroom»;

- полезные советы: 10 вопросов, от ответа на которые неуйти» (о том, как разговорить своих учеников) или, например, «Как разговорить подростков», или «Как определить уровень ученика без тестов»;

- english-teachers-upgrade https://www.instagram.com/english_teachers_ upgrade/ - сообщество креативных преподавателей. Очень полезный ресурс, на котором можно найти советыпосамым разным вопросам, касающимсяпреподавания английского языка. Хотелось бы отметить следующие разделы. Например:

- рубрики «Teaching Tips», «Teaching Life Hacks», «Let's Help with Advice», «We Recommend», «Let's Discuss», «Books Review», «Lesson Plan», «Activities» и др.; 
- советы тем преподавателям, которые преподают или хотели бы преподавать on-line: «Online Helpers», «From Offline to Online», «Top 5 Tools for a Perfect Online Lesson», «How to Find Online Students» и другие;

- teaching_and_learning_tips https://www.instagram.com/teaching_and_learning_ tips/ - блог Анны Свинцовой, основателя школы изучения иностранных языков, г. Пермь. Автор щедро делится со всеми желающими своими наработками, секретами успешного преподавания английского языка. Здесь можно найти идеи и ресурсы для повышения эффективности преподавания, например, планы уроков по разным темам, примеры использования игр на уроках, с подробным описанием методики их применения, проверить и повысить свой уровень с точки зрения методики преподавания, пройдя онлайн курс «Natural Teacher»;

- linguapolisgame https://www.instagram.com/linguapolisgame/ - английские настольные игры. На этой страничке представлены примеры настольных игр для уроков с подробным описанием методики работы с ними, даны ответы на часто задаваемые вопросы, а также полезные советы о том, как применить такие игры на онлайн уроке иностранного языка. Даются идеи как самому сделать подобные игры;

- easylanguageschool https://www.instagram.com/easylanguageschool/ — или «Английский из Англии». Блог ведет Алла Пимм, дипломированный преподаватель, обладатель сертификатов CELTA, IELTS, лингвист-переводчик. Ресурс подходит как для изучающих английский язык, так и для преподавателей;

- fabula_world https://www.instagram.com/fabula_world/ - дидактические игры для изучения иностранных языков. На сайте можно скачать и распечатать игры, лэпбуки, календари, самые разные декоративные элементы для украшения помещения к праздникам. Все материалы можно распечатать в PDF-формате;

- powerthesaurus https://www.instagram.com/powerthesaurus/ - справочный веб-сайт будет полезен изучающим английский язык. Здесь предлагаются иллюстрированные схемы и таблицы по темам «Синонимы», «Антонимы», «Идиомы».

Подводя итог нашего обзора, следует отметить, что в настоящее время глобальная сеть Интернет предоставляет студентам и преподавателям не только практически неограниченные возможности межкультурного и межнационального общения, но и прекрасные перспективы для самообразования и саморазвития, повышения общего уровня языковой компетенции.

Несомненно, интернет-ресурсы - это мощное средство повышения эффективности всего процесса обучения иностранным языкам. С одной стороны, не выходя за пределы учебной аудитории, студенты имеют доступ к образовательным ресурсам сети и оказываются таким образом вовлечёнными в глобальное межъязыковое пространство. С другой стороны, нельзя недооценивать важность современных образовательных веб-сайтов и для преподавателя, так как они являются тем ценным источником, из которого можно почерпнуть множество интересных идей или использовать уже разработанные игры, викторины для оживления своего урока иностранного языка.

С нашей точки зрения, представленные выше источники будут также полезны начинающим преподавателям, так как на некоторых сайтах для пользователей есть доступ к готовым планам уроков. При всех многочисленных возможностях современных обучающих сайтов и платформ перед образовательными учреж- 
дениями таким образом встаёт необходимость обеспечения аудиторного фонда современной компьютерной техникой и доступом в Интернет.

\section{СПИСОК ЛИТЕРАТУРЫ}

Баранова, Н. А., Дубинина А. С. (2015) Преимущества использования Интернетресурсов при обучении иностранным языкам [Электронный ресурс] // Концепт. № 7. URL: http://e-koncept.ru/2015/15255.htm (дата обращения: 02.03.2020).

Тер-Минасова, С. Г. (2009) «Иностранный язык» для неязыковых вузов и факультетов: примерная программа. М.: Министерство образования и науки РФ. 24 с.

Николаева Татьяна Андреевна - доцент кафедры иностранных языков Московского гуманитарного университета. Адрес: 111395, Россия, г. Москва, ул. Юности, д. 5 Тел.: +7 (499) 374-75-92. Эл. адрес: t.nikolaeva@list.ru

Заеко Ольга Вадимовна - доцент кафедры иностранных языков Московского гуманитарного университета. Адрес: 111395, Россия, г. Москва, ул. Юности, д. 5. Тел.: +7 (499) 374-75-92. Эл. адрес: romanyk_vit@mail.ru

Nikolaeva Tatyana Andreyevna, Associate Professor, Department of Foreign Languages, Moscow University for the Humanities. Postal address: 5, Yunosti St., Moscow, Russian Federation, 111395. Tel.: +7 (499) 374-75-92. E-mail: t.nikolaeva@list.ru

Zaeko Olga Vadimovna, Associate Professor, Department of Foreign Languages, Moscow University for the Humanities. Postal address: 5, Yunosti St., Moscow, Russian Federation, 111395. Tel.: +7 (499) 374-75-92. E-mail: romanyk_vit@mail.ru

\section{Для цитирования:}

Николаева Т. Н., Заеко О. В. Обзор Интернет-ресурсов, применяемых в процессе обучения английскому языку // Научные труды Московского гуманитарного университета. 2020. №2. C. 20-27. DOI: 10.17805/trudy.2020.2.4 